\title{
REPRESENTAÇÕES DE MEIO AMBIENTE E EDUCAÇÃO AMBIENTAL: um estudo com docentes de casas familiares rurais
}

\author{
REPRESENTATIONS OF ENVIRONMENT AND ENVIRONMENTAL \\ EDUCATION: a study with teachers from Rural Family Homes
}

\author{
Edival Sebastião Teixeira* \\ Fernanda Luiza Algeri**
}

\begin{abstract}
Resumo
Este artigo resulta de pesquisa que teve por objetivo analisar as representações sociais de meio ambiente de docentes que atuam em Casas Familiares Rurais da região sudoeste do Paraná. Para a coleta de dados utilizouse um instrumento composto de três partes: a primeira concentrava dados de identificação; a segunda continha questões abertas centradas nas concepções dos docentes sobre desenvolvimento sustentável, educação e pedagogia da alternância; a terceira consistia numa questão de evocação livre, tendo como termo indutor a expressão meio ambiente. Os resultados obtidos sugerem que a representação social de meio ambiente dos sujeitos está diretamente relacionada com o seu contexto de educadores do campo e com as mediações propiciadas pela condução do trabalho pedagógico segundo o método da pedagogia da alternância. Foi identificada certa perspectiva de Educação Ambiental que prioriza a mudança de comportamento e de atitude das pessoas perante os problemas ambientais.
\end{abstract}

Palavras-chave: Representações sociais. Meio ambiente. Educação ambiental. Casa Familiar Rural.

\begin{abstract}
This paper results from a research aimed to analyse the social representations of environment held by teachers who work at Rural Family Homes located in the southwest of Paraná, Brazil. The data were collected using an instrument composed of three parts: the first focused on identification data; the second contained open-ended questions focused on teachers' conceptions of sustainable development, education and pedagogy of alternation; the third consisted of a free-association question, based on the term environment. The results suggest that the social representation of environment held by the subjects is directly related with their work as rural educators and with the mediation provided by the pedagogy work being conducted according to the alternation pedagogy method. A certain perspective of environmental education that favours the change of people's behaviour and attitude towards environmental issues could be identified.
\end{abstract}

Keywords: Social representations. Environment. Environmental education. Rural Family Home.

\section{Introdução}

De acordo com Franco (2004), valorizar o estudo das representações sociais em campos como o da educação e o da psicologia representa um avanço, tendo em vista as grandes contribuições dessa abordagem para as ciências psicossociais. Essa também parece ser a opinião de Cavalcante e Minayo $(2009$, p. 58 ), para quem estudar uma representação social consiste numa forma de conhecer o modo como determinado grupo humano constrói um conjunto de saberes, expressa sua identidade, "atribui sentido a uma diversidade de objetos e, principalmente, constrói códigos culturais que definem, em cada momento histórico, as regras de uma comunidade". Concordando-se com essas autoras, há

\footnotetext{
Professor adjunto da Universidade Tecnológica Federal do Paraná Coordenador do Programa de Pós-Graduação em Desenvolvimento Regional. E-mail: edival@utfpr.edu.br

" Aluna de Iniciação Científica na Universidade Tecnológica Federal do Paraná UTFPR - Campus Pato Branco. Grupo de Pesquisa GEPEL. E-mail: fernandaalgeri@hotmail.com
}

que se admitir, então, que a teoria das representações sociais serve como referencial para estudar o comportamento humano nos mais variados contextos.

De fato, essa teoria tem sido amplamente utilizada como referencial para pesquisa em diversos campos no Brasil, dentre os quais podemos citar como exemplos o da saúde pública e o da educação. No campo da saúde pública, os estudos cobrem tanto aspectos como representações sociais de profissionais de saúde, a respeito de temas diversos, quanto aspectos relacionados às representações sociais de usuários desses serviços. A título de exemplo mencionaremos apenas três estudos recentes na área: o primeiro consiste em pesquisa realizada por Leite e Veloso (2009), que analisaram as representações sociais que profissionais de equipes do Programa Saúde da Família desenvolvem sobre esse programa; o segundo é constituído por uma investigação de Gastal e Gutfreind (2007) 
sobre as representações sociais de direito à saúde em dois grupos de usuários; e o terceiro estudo é o de Cavalcante e Minayo (2009). Essas autoras identificaram e analisaram as representações sociais de profissionais, gestores e familiares acerca dos direitos de crianças e adolescentes portadores de deficiência que foram vítimas de violência.

Também no campo da educação os estudos que se utilizam do referencial teórico das representações sociais cobrem diversos aspectos, dentre os quais destacamos o da Educação Ambiental. Nesse sentido, podemos citar como exemplo os estudos de Brandalise et al. (2009), que investigaram a percepção ambiental de universitários em relação ao que esses autores chamam de grau de Educação Ambiental. Por sua vez, Schwarz, Sevegnani e André (2007) analisaram desenhos infantis com o intuito de identificar nessas produções as representações sociais de Mata Atlântica e de sua biodiversidade em crianças residentes em área urbana de Joinville, Santa Catarina. Já na diretriz indicada por Reigota (2007), Abreu, Campos e Aguilar (2008) dedicaram-se ao estudo das concepções orientadoras da prática docente em Educação Ambiental desenvolvidas em escolas de Educação Básica na cidade de Ribeirão Preto, São Paulo. Martinho e Talamoni (2007) também estudaram representações sociais de escolares de pouca idade. Nesse caso, esses estudiosos analisaram as representações de meio ambiente em crianças do Ensino Fundamental de uma escola rural e uma escola urbana de um município do interior paulista.

Em rápida olhada aos trabalhos mencionados, pode-se observar que, apesar de o referencial teórico ser comum, existe uma pluralidade quanto às técnicas de coleta e análise de dados, sendo, também, que em todos os estudos verifica-se a utilização de mais de uma técnica, embora todas elas focalizem uma ou outra forma de linguagem, mediação privilegiada das representações sociais (MINAYO, 2008).

O trabalho ora apresentado é parte de uma pesquisa ampla e em andamento, que focaliza a relação entre a educação do campo, na perspectiva da pedagogia da alternância praticada pelas Casas Familiares Rurais da região sudoeste do Paraná, e o desenvolvimento sustentável da agricultura familiar. Um dos focos dessa investigação consiste na identificação e análise de aspectos da proposta didático-pedagógica da pedagogia da alternância possivelmente relacionados com o desenvolvimento socioeconômico e ambiental das famílias cujos filhos frequentam essas instituições de ensino. $E$ é desse foco que se origina o presente artigo.

A dinâmica da pedagogia da alternância objetiva proporcionar vínculos educativos entre os tempos e espaços de formação vivenciados alternadamente na instituição de ensino, na comunidade e na propriedade agrícola da família do jovem. Por isso, no início de cada ano letivo elabora-se um plano de formação com temas geradores debatidos com as famílias e as lideranças comunitárias, para que o processo de ensino esteja conectado com os interesses e necessidades da agricultura familiar. Dessa forma, procura-se integrar processos de ensino e aprendizagem organizados com demandas e interesses advindos das famílias, com o intuito de que temas e habilidades técnicas tratados no campo do ensino formal possam converter-se em novas experiências dos alunos em suas propriedades, incentivando a adoção de inovações, quando pertinentes, bem como a avaliação de seus resultados.

Quatro princípios norteiam a pedagogia da alternância que se pratica nas Casas Familiares Rurais: 1) o próprio método da alternância; 2) a ênfase na formação integral do jovem; 3) a participação das famílias na condução do projeto educativo e na gestão da escola; 4) o desenvolvimento do meio (GIMONET, 2007). Por conseguinte, esse método pedagógico preconiza que se deve levar em conta a realidade das propriedades rurais e das comunidades dos alunos, com o propósito de identificar possibilidades tanto para o desenvolvimento "sustentável" das propriedades como para a permanência dos jovens no campo. E como não é possível falar em agricultura sem levar em conta a questão ambiental, como também não é possível falar de desenvolvimento sustentável sem levar em conta o ambiente e os sujeitos, ambas as temáticas - sustentabilidade e Educação Ambiental - são cruciais para a pedagogia da alternância.

O conceito de desenvolvimento sustentável como um processo que busca articular as dimensões da natureza e da sociedade vem ganhando destaque como estratégia para enfrentar os problemas sociais oriundos da falta de uma distribuição mais equitativa dos benefícios do crescimento econômico e, também, os problemas ambientais gerados pelo modelo de desenvolvimento economicista de progresso. Tal modelo considerou os recursos naturais apenas como meio para o desenvolvimento econômico, sem levar em consideração a dinâmica da natureza.

O modelo de desenvolvimento como progresso econômico por certo tem vantagens. Contudo, é preciso aprimorá-lo, visando a remodelar os pontos em que não se está obtendo resultados positivos, sobretudo no que concerne a uma distribuição mais equitativa dos resultados. Com efeito, apenas dispor de recursos para gerar resultados está longe de ser condição suficiente para preparar um melhor futuro para a massa da população. Assim, "quando o projeto social prioriza a efetiva melhoria das condições de vida dessa população, o crescimento se metamorfoseia em desenvolvimento" (FURTADO, 2004, p. 484). 
De acordo com Barbieri (2003), o termo desenvolvimento sustentável resulta do encontro da palavra desenvolvimento - que nos remete à ideia de crescimento econômico, da extração de recursos naturais sem a preocupação com a reprodução dos mesmos - e da palavra sustentável, a qual significa a capacidade de os ecossistemas se reproduzirem, ou seja, de se preservar seus recursos naturais.

Portanto, a ideia de desenvolvimento sustentável é bem mais ampla, porque implica a necessidade de preservar e expandir as liberdades substantivas propiciadas em parte pelo crescimento econômico, mas sem comprometer a possibilidade de as futuras gerações desfrutarem de liberdade semelhante ou maior.

No que concerne à agricultura, o termo desenvolvimento sustentável indica a utilização de tecnologias que não agridam o meio ambiente como estratégia de desenvolvimento agrícola que neutralize ou minimize os efeitos das perturbações antrópicas no meio ambiente. Nesse sentido, a sustentabilidade de um agroecossistema tem a ver com a habilidade de manter a produção através do tempo, em face de distúrbios ecológicos e pressões socioeconômicas de longo prazo. (ALTIERI, 1989).

Trata-se, pois, de um novo modelo de desenvolvimento e de agricultura que seja socialmente justo, economicamente viável, ecologicamente sustentável e culturalmente aceito, que recupere técnicas, valores e tradições e que seja, portanto, capaz de redimensionar as relações da sociedade com a natureza, buscando soluções para condicionar a produção à capacidade de suporte dos recursos naturais. (ALMEIDA, 1997).

Considerando-se a relevância da questão ambiental no contexto da agricultura familiar, procurou-se analisar as representações sociais de meio ambiente de docentes das casas familiares rurais localizadas na região sudoeste do Paraná, partindo-se do pressuposto de que tais representações orientam práticas pedagógicas, sobretudo no tocante à Educação Ambiental. É desse aspecto da pesquisa ampla mencionada antes que se ocupa o presente trabalho.

\section{Representações sociais de meio ambiente e Educação Ambiental}

A teoria das representações sociais surgiu nos anos de 1960, a partir das pesquisas de Serge Moscovici sobre os modos como a psicanálise penetrou no pensamento popular francês (MOSCOVICI, 2003; DUVEEN, 2003; MARKOVÁ, 2006). Ao contrário do conceito de representações coletivas de Durkheim, Moscovici afirma que as representações sociais são dinâmicas e sujeitas à variação e à diversidade que caracterizam a sociedade moderna.

Para Serge Moscovici (2003), as representações sociais consistem num sistema de valores, ideias e práticas que tem a função de possibilitar às pessoas orientar e controlar seu mundo material e social, bem como possibilitar a comunicação dos membros de determinada comunidade, na medida em que fornece um conjunto de códigos que nomeiam e classificam, sem ambiguidades, os vários aspectos de sua realidade. Para o autor, a teoria das representações sociais toma como ponto de partida "a diversidade dos indivíduos, atitudes e fenômenos, em toda sua estranheza e imprevisibilidade", tendo por objetivo "descobrir como os indivíduos e grupos podem construir um mundo estável, previsível, a partir de tal diversidade". (MOSCOVICI, 2003, p. 79).

Segundo o autor, nós experienciamos e percebemos um mundo com o qual estamos familiarizados utilizando ideias ou coisas feitas por nós mesmos para representar ou explicar fenômenos naturais ou sociais. Assim, as representações têm duas funções: convencionalizar os objetos, as pessoas e as ideias, de modo que cada experiência seja vivida numa realidade predeterminada por convenções que definem as fronteiras entre o que é significativo e o que não o é; e prescrever, no sentido de quase impor, um modo de ser e de pensar que já está presente no contexto social em que vivemos antes mesmo que sejamos capazes de pensar (MOSCOVICl, 2003). Dizendo-se de outra maneira, as representações sociais orientam e, em certa medida, determinam condutas.

Dois processos cognitivos, a ancoragem e a objetivação, geram e dão sustentação às representações. A ancoragem é o mecanismo pelo qual o sujeito reduz o desconhecido a categorias e imagens, as quais, por sua vez, são sempre contextualizadas relativamente a algo familiar. Dessa forma, pela ancoragem o sujeito transforma algo perturbador e que o intriga em seu próprio sistema de categorias, e o compara com paradigmas ou categorias que pensa serem mais apropriados. Em outras palavras, o sujeito compara seu sistema de categorias com determinados sistemas de classificação ou de nomeação.

Mais especificamente no que diz respeito ao conceito de ancoragem, Moscovici (2003) afirma que a teoria das representações sociais tem duas consequências: "em primeiro lugar, ela exclui a ideia de pensamento ou percepção que não possua ancoragem" (MOSCOVICl, 2003, p. 70); em segundo lugar, os sistemas de classificação e nomeação não são simplesmente meios para rotular ou graduar pessoas ou objetos, pois, com efeito, 
não podemos esquecer que interpretar uma idéia ou um ser não-familiar sempre requer categorias, nomes, referências, de tal modo que a entidade nomeada possa ser integrada na "sociedade de conceitos" de Gombrich. Nós os fabricamos com esta finalidade, na medida em que os sentidos emergem, nós os tornamos tangíveis e visíveis e semelhantes às idéias e seres que nós já integramos e com os quais nós estamos familiarizados. (MOSCOVICl, 2003, p. 70).

A objetivação, por sua vez, é o meio pelo qual tornamos algo abstrato em algo concreto. Ou seja, aquilo que apenas está em nossa mente, como intangível, é transformado em algo "quase tangível" pelo processo de objetivação. Esse processo, portanto, explica a passagem de um ente imaginário para a realidade material, como, por exemplo, a passagem de um pensamento a um ato de comportamento manifesto.

Nas palavras de Moscovici (2003, p. 71-72), a

objetivação une a idéia de não-familiaridade com a de realidade, torna-se a verdadeira essência da realidade. Percebida primeiramente como um universo puramente intelectual e remoto, a objetivação aparece, então, diante de nossos olhos, física e acessível. [...] objetivar pé descobris a qualidade icônica de uma idéia, ou ser impreciso; é reproduzir um conceito em uma imagem. Comparar é já representar, encher o que está naturalmente vazio, com substância. (MOSCOVICI, 2003, p. 71-72).

Segundo Franco (2004, p. 172), a objetivação "cristaliza-se a partir de um processo figurativo e social e passa a constituir o núcleo central de uma determinada representação, seguidamente evocada, concretizada e disseminada como se fosse o real daqueles que a expressam". É possível, pois, afirmar que toda representação social organiza-se em torno de um núcleo central, o qual determina, ao mesmo tempo, sua significação e sua organização interna. Esse núcleo é composto por um ou mais elementos cuja ausência desestruturaria a representação ou lhe daria uma significação completamente diferente (SÁ, 1996).

O núcleo central de uma representação define, em certo sentido, uma base relativamente estável e coletivamente partilhada acerca de determinados aspectos da realidade. Por essa razão, esse núcleo - além de marcado pela memória coletiva está muito relacionado com as condições históricas, sociais, ideológicas etc., inerentes ao contexto de um grupo social.

Por isso, o núcleo central caracteriza-se por ser estável e resistente a mudanças. Mas, por outro lado, o fato de ser relativamente independente do contexto social e material imediato no qual a representação é posta em evidência, assegura a continuidade e a permanência de uma representação por tempos mais ou menos longos (POLLI et al., 2009).
Em torno do núcleo central organiza-se um sistema periférico, o qual permite integrar as experiências e as histórias individuais às grupais, comportando, portanto, a heterogeneidade e as idiossincrasias. É esse sistema periférico que possibilita a diferenciação do conteúdo de uma representação entre os diversos sujeitos, ao mesmo tempo em que facilita a adaptação de outra representação à realidade imediata.

\section{Portanto, é o sistema periférico que}

promove a interface entre a realidade concreta e o núcleo central, atualizando-o e contextualizando-o constantemente, daí resultando sua mobilidade e flexibilidade, permitindo a expressão individualizada e tornando possível que a representação social se ancore na realidade do momento. (CROMACK; BURSZTYN; TURA, 2009, p. 628).

Tendo em vista que nossas ações estão ancoradas em determinadas visões de mundo ou representações, e considerando que as representações sociais enquanto processos que têm a capacidade de orientar condutas sustentam práticas pedagógicas escolares no âmbito da Educação Ambiental, parece necessário identificar 0 que professores pensam sobre meio ambiente. Justifica-se essa afirmação, pois toda prática pedagógica veicula conhecimento científico, mas também um conjunto de comportamentos, valores e atitudes que passarão a ser esperados de quem os detém, ou de quem passará a detê-los. Dizendo-se de outra forma, as práticas pedagógicas têm a finalidade influenciar outrem "visando interferir em sua forma de agir, pensar, se comportar ou se expressar" (ALMEIDA, 2005, p. 183).

Considerando então a não neutralidade das ações humanas, no que diz respeito à educação formal a própria definição de objetivos e dos modos pelos quais se buscará atingi-los já pressupõe interesses que regem escolhas quanto aos conteúdos e métodos pensados como necessários. Por sua vez, essas escolhas podem estar implícitas ou explícitas nas diretrizes oficiais que ordenam os sistemas de ensino, bem como em documentos pedagógicos das próprias escolas, mas, certamente, estão explícitas nos planejamentos e na prática cotidiana dos professores, ainda que eles possam eventualmente não se dar conta disso.

Logo, parece adequado supor que, enquanto processos que têm a capacidade de orientar condutas, as representações sociais sustentam práticas pedagógicas escolares no âmbito da Educação Ambiental, ainda que professores e estudantes não tenham se dado conta desse fato. Nesse sentido, concordamos com Reigota (2007), para quem "o primeiro passo para a realização da educação ambiental deve ser a identificação das representações das pessoas envolvidas no processo educativo" (REIGOTA, 2007, p.14). 
Desde as Conferências de Estocolmo, em 1972, e de Tbilisi, em 1975, quando foram elaborados princípios e orientações para a educação ambiental, esta temática tem estado muito presente nas discussões sobre educação de um modo geral (LEFF, 2001; JACOBI, 2003; REIGOTA, 2007).

$\mathrm{O}$ que ambiciosamente se pretende com a Educação Ambiental é a superação da dicotomia entre sociedade e natureza, mediante um conjunto de práticas pedagógicas alicerçadas na ideia de que o ambiente se constitui como um campo de interações culturais, sociais e naturais (CARVALHO, 2004). Contudo, se de um lado não há consenso sobre o que se conceitua como meio ambiente (REIGOTA, 2007), de outro há diferentes perspectivas de Educação Ambiental.

Uma dessas perspectivas é denominada por Guimarães (2006) como "educação ambiental conservadora", a qual focaliza apenas o comportamento dos indivíduos em relação às suas práticas no ambiente. Para esse mesmo autor, trata-se de uma visão ingênua e que leva a uma prática conservadora por não favorecer a percepção das "relações de poder que engendram a realidade socioambiental, e simplista por estabelecer relações lineares (não complexas) de causa e efeito dos fatos sociais" (GUIMARÃES, 2006, p. 25).

Outra concepção é a que vem sendo denominada por alguns autores como educação ambiental crítica e transformadora (JACOBI, 2003; GUIMARÃES, 2000, 2006, 2007; LOUREIRO, 2004a, 2004b, 2006). Nessa perspectiva, a educação é compreendida como uma prática social que, por ser vinculada à história, deve problematizar a realidade, produzindo e reproduzindo reflexões que forcem a transformação da realidade e não apenas a mudança de comportamentos frente aos problemas ambientais. Trata-se, pois, de uma educação que procura trazer à tona a consciência de que os problemas socioambientais são problemas antes de tudo políticos, econômicos e culturais, no sentido de que são gerados e mantidos pelo capitalismo. Por isso, nessa perspectiva de Educação Ambiental, a transformação da relação das pessoas com o ambiente está inserida num contexto maior que exige mudanças no nosso modo de vida em sociedade.

\section{$O$ contexto da pesquisa}

Casas Familiares Rurais (CFRs) são instituições de ensino que se originaram em meados da década de 1930 na França, como alternativa à educação escolar oferecida para os filhos de pequenos agricultores franceses de então. Com o passar dos anos, desenvolveu-se um método pedagógico que se caracteriza por alternar tempos e espaços forma- tivos, os quais são vivenciados pelos estudantes no ambiente escolar propriamente dito e nos ambientes familiar e comunitário. Advém daí sua denominação como pedagogia da alternância.

Atualmente a pedagogia da alternância é praticada em inúmeros países de todos os continentes. A experiência brasileira com o método da alternância teve início em 1969, no Espírito Santo, e hoje se encontra em praticamente todos os estados da federação.

Na região Sul do Brasil, a primeira Casa Familiar Rural surgiu em 1987, na zona rural do município de Barracão (atualmente faz parte do município de Bom Jesus do Sul), no extremo sudoeste paranaense, na fronteira com a província argentina de Misiones. A CFR mais recente do Paraná entrou em funcionamento em 2010, no município de Realeza.

Em todo o Estado do Paraná existem atualmente 42 CFRs, das quais 17 estão instaladas na região sudoeste. Todas essas instituições fazem parte da Associação das Casas Familiares Rurais do Sul do Brasil (ARCAFAR/SUL).

As CFRs do sudoeste do Paraná estão localizadas nos seguintes municípios: Bom Jesus do Sul, Capanema, Chopinzinho, Coronel Vivida, Dois Vizinhos, Enéas Marques, Francisco Beltrão, Manfrinópolis, Marmeleiro, Nova Prata do Iguaçu, Pato Branco, Pérola do Oeste, Santa Izabel do Oeste, São Jorge do Oeste, Santo Antônio do Sudoeste, Sulina e Realeza. A CFR deste último município não foi envolvida na pesquisa porque iniciou suas atividades depois que a investigação já estava em andamento.

Na região sudoeste do Paraná essas instituições ministram cursos de Ensino Fundamental (EF) e Ensino Médio (EM), nos quais, além dos conteúdos curriculares da base nacional, os jovens estudam outros conteúdos apropriados para a atividade na agricultura. Nas CFRs de Chopinzino, Coronel Vivida, São Jorge do Oeste e Santo Antônio do Sudoeste os cursos de EM são técnico-profissionalizantes: Gestão Ambiental, Técnico em Alimentos, Técnico em Agroecologia e Técnico em Agropecuária, respectivamente. Já nas CFRs de Bom Jesus do Sul, Capanema, Dois Vizinhos, Manfrinópolis, Marmeleiro, Nova Prata do Iguaçu, Pato Branco, Pérola do Oeste, Santa Izabel do Oeste, Francisco Beltrão, Sulina e Enéas Marques, tanto os cursos de EF quanto os de EM são genericamente denominados como cursos de Qualificação em Agricultura. Todas essas instituições utilizam o modelo da pedagogia da alternância, cujo método de ensino segue uma dinâmica própria ajustada a certas especificidades do trabalho na agricultura.

No ano letivo de 2010, o total de alunos matriculados nas CFRs pesquisadas era 835 , sendo 645 meninos e 190 meninas. Os egressos somavam 
1.715, sendo 1.233 meninos e 482 meninas. Há predominância da formação de meninos, com exceção de Bom Jesus do Sul, cuja Casa Familiar vem formando mais meninas que meninos desde sua fundação.

Em geral, nas CFRs do sudoeste do Paraná, segundo depoimentos das equipes pedagógicas, há mais dificuldades de atender às meninas porque um dos principais motivos é o fato de que o regime de internato alternado (uma semana na Casa Familiar Rural e outra na família, e assim consecutivamente) "assusta" muitos pais, que dizem não se sentir à vontade para deixar suas filhas junto com os meninos. Outro motivo apontado pelas equipes tem a ver com o fato de que as meninas não tendem a desenvolver seus conhecimentos técnicos, influenciadas pelo contexto familiar e social, em que o trabalho da mulher agricultora, em geral, é visto como acessório ou secundário, sendo vinculado "às coisas da casa", como já apontava a pesquisa realizada por Martinelli e Corona (2007). Por isso, segundo os mesmos depoimentos, a migração campo/cidade das meninas, que se empregam em geral como domésticas, tem sido maior que a dos meninos.

Quanto ao corpo de servidores técnico-administrativos e docentes, nas CFRs sudoestinas o mesmo é constituído por monitores, que geralmente são egressos de cursos superiores da área das ciências agrárias; por professores, que são docentes da rede pública do Estado do Paraná cedidos para atuar nas CFRs; e pelos demais profissionais, os quais são responsáveis pelos serviços administrativos, limpeza, cozinha e manutenção em geral.

Todas as construções variam de 300 a 800 $\mathrm{m}^{2}$, estão em bom estado de conservação e são, em geral, de alvenaria, com exceção das de Coronel Vivida e Santa Izabel, que são mistas (madeira e alvenaria). As CFRs têm energia eletrifica, telefone e estão ligadas à rede mundial de computadores. Os dormitórios são separados em ala feminina e masculina, e em geral abrigam de oito a dez alunos por dormitório.

As CFRs pesquisadas possuem horta para consumo próprio, com diferenças no tamanho e variedade de culturas. Quanto aos alimentos, a maior quantidade e as variedades originam-se das famílias dos alunos, mas há também uma parte proveniente dos programas públicos de merenda escolar e demais doações das comunidades atendidas.

\section{Método de coleta e tratamento dos dados}

A investigação como um todo envolveu as 16 Casas Familiares Rurais da região sudoeste do Paraná que estavam em funcionamento na época em que os dados foram coletados. Dentre os 120 profissionais que compõem as equipes pedagógicas dessas instituições, a pesquisa contou com a adesão voluntária de 69 docentes, de ambos os sexos e com os mais variados tempos de experiência na docência, em geral, e na pedagogia da alternância, em particular.

A identificação de representações sociais pode ser feita a partir de diversas formas de manifestação comportamental de indivíduos ou de grupos. No entanto, sua mediação privilegiada "é a linguagem, tomada como forma de conhecimento e de interação social" (MINAYO, 2008, p. 108). Por conseguinte, ainda que, por um lado, não seja adequado estabelecer uma técnica padrão de pesquisa em representações sociais, por outro, as técnicas focadas nas diversas formas de manifestação da linguagem, ou do simbólico, são as mais adequadas, senão as únicas possíveis.

Diante disso, para a coleta de dados foi utilizado um instrumento composto por três partes: a primeira concentrava dados de identificação; a segunda continha questões abertas centradas nas concepções dos docentes sobre desenvolvimento sustentável, educação e pedagogia da alternância; a terceira consistia numa questão de evocação livre, tendo como termo indutor a expressão "meio ambiente". Nessa última questão solicitava-se que os sujeitos escrevessem as quatro primeiras palavras que lhes viessem à mente mediante o termo indutor e assinalassem as duas palavras que consideravam como as mais importantes; por fim, os sujeitos deviam justificar suas evocações e escolha das palavras mais importantes.

A coleta de dados foi realizada durante visitas previamente agendadas às Casas Familiares Rurais. Os sujeitos foram informados sobre os objetivos da pesquisa, sendo que todos os que concordaram em participar assinaram um termo de consentimento livre e esclarecido.

Como técnica de tratamento dos dados obtidos mediante as questões dissertativas optou-se pela análise de conteúdo, tendo em vista que essa técnica considera a semântica da língua e a interpretação do sentido que um indivíduo atribui à mensagem.

Sobre essa técnica de tratamento de dados, vários autores a conceituam como uma técnica adequada a objetos de estudo tais como o desta pesquisa. Para Bardin (2002), por exemplo, trata-se de "um conjunto de técnicas de análise 
das comunicações que utiliza procedimentos sistemáticos e objetivos de descrição do conteúdo das mensagens" (BARDIN, 2002, p. 38). Por sua vez, Minayo (2003) enfatiza que a análise de conteúdo visa a descobrir o que está por trás de cada conteúdo manifesto: "o que está escrito, falado, mapeado, figurativamente desenhado e/ou simbolicamente explicitado sempre será o ponto de partida para a identificação do conteúdo manifesto (seja ele explícito e/ou latente)" (MINAYO, 2003, p. 74).

Por sua vez, os dados obtidos pela questão de evocação livre foram organizados e tratados de acordo com os procedimentos da teoria do núcleo central das representações sociais descritos por Sá (1996), com o auxílio do programa Excel $\AA$, tal como executado por Castro (2004) em seu estudo sobre a representação social de ciência em estudantes do Ensino Fundamental.

Primeiramente foram identificadas todas as palavras evocadas pelos sujeitos mediante o termo indutor "meio ambiente". A seguir, essas palavras foram organizadas em 40 categorias distintas de acordo com a proximidade semântica entre os vocábulos e as justificativas dadas pelos participantes para as escolhas feitas. A frequência média de evocação por categoria encontrada foi igual a seis.

A partir dessa categorização prévia, elegemos para análise as categorias mais salientes, isto é, aquelas que tiveram evocações iguais ou superiores à média. Nessa nova configuração foram identificadas 13 categorias cujos vocábulos que as compõem foram evocados 207 vezes. A seguir, foi calculada a frequência média de evocação (fme) por categoria mais saliente, cujo valor encontrado foi de 15 vocábulos, desprezando-se as casas decimais.

Para o cálculo da média das ordens médias de evocação foi utilizado o seguinte procedimento: a) determinação da frequência de cada categoria segundo a ordem de evocação; b) cálculo da frequência ponderada de cada categoria mediante a atribuição de pesos de um a quatro, conforme a ordem de evocação; c) cálculo da ordem média de evocação por categoria (ome), obtida através da divisão da somatória das frequências ponderadas pela frequência de cada categoria; d) determinação da média das ordens médias de evocação através da divisão da somatória das médias de evocação por categoria pelo número de categorias.

Finalmente, as categorias foram organizadas em um quadro de acordo com a frequência média de evocação e com a frequência e a ordem média de evocação, o qual permitiu visualizar os elementos mais suscetíveis de pertencer ao núcleo central e os elementos mais periféricos da representação social de meio ambiente dos sujeitos da pesquisa.

\section{Caracterização dos participantes da pesquisa}

Participaram voluntariamente da pesquisa 69 docentes, entre monitores e professores de ambos os sexos, atuantes em 13 das 16 instituições visadas na pesquisa. Monitores são profissionais egressos das ciências agrárias, de nível superior ou não, cuja função é ministrar as disciplinas técnicas e acompanhar os alunos em suas atividades práticas nas propriedades das famílias ou na comunidade. Esses profissionais geralmente são contratados pela ARCAFAR/SUL. Os professores, por sua vez, são cedidos pela Secretaria de Estado da Educação do Estado do Paraná e ministram as disciplinas do currículo oficial.

$\mathrm{Na}$ região sudoeste do Paraná observa-se uma inversão nas proporções entre homens e muIheres, quando se compara o tipo de atuação docente na pedagogia da alternância entre monitores e professores. Na educação escolar em geral a docência é predominantemente feminina e isso se reflete nas CFRs, quando se levam em conta as disciplinas do currículo oficial: são 13 professores e 32 professoras. Contudo, para as disciplinas específicas da área agrícola são 17 monitores e sete monitoras.

Considerando que as 16 CFRs do sudoeste do Paraná pesquisadas foram criadas há mais de dez anos, chama a atenção o tempo médio de experiência dos monitores e professores com a pedagogia da alternância, ainda que estes tenham, em média, o dobro do tempo de experiência daqueles.

Dentre os 24 monitores, considerando os dois sexos, apenas oito (dos quais cinco têm formação de nível superior) contam com seis ou mais anos de experiência. Os demais 16 monitores têm entre dois meses e três anos de experiência na função.

Em relação aos professores, o quadro é mais preocupante. Dentre os 45 docentes, considerando ambos os sexos, apenas um tem 12 anos de experiência em CFR e outro tem sete anos. Todos os demais variam entre um mês e quatro anos de experiência com a pedagogia da alternância, sendo esses últimos, no entanto, apenas quatro.

Esses dados sugerem fortemente que existe alta rotatividade de monitores e professores nas CFRs. No que diz respeito aos primeiros, o problema tem a ver com os baixos salários e com as dificuldades que a ARCAFAR/SUL enfrenta para mantê-los em dia. Quanto aos professores, o problema não é tanto o da remuneração, pois esses profissionais são pagos pelo governo do Paraná.

Em entrevistas que realizamos com coordenadores e professores das CFRs, parecem emergir dois fatores principais para a alta 
rotatividade desses profissionais. Em primeiro lugar, trata-se de que a maioria dos professores tem vínculo empregatício precário, uma vez que não foram contratados mediante concurso público. Em segundo lugar, os professores do quadro permanente do magistério relutam em aceitar aulas nas CFRs porque, segundo nos disse um coordenador entrevistado, eles perdem alguns privilégios, tais como a possibilidade de trabalhar 20 horas extraordinárias e, ao final de um mês, receber por 60 horas semanais de trabalho. Além disso, os professores do quadro permanente não se dispõem a fazer algumas atividades típicas do método da alternância, como, e principalmente, ir às propriedades rurais acompanhando os monitores nas visitas às famílias dos alunos.

$\mathrm{Na}$ opinião dos professores participantes da pesquisa, a alta rotatividade no quadro de docentes parece não ter implicações no desempenho acadêmico dos jovens das CFRs: os professores dizem não observar diferenças significativas quando comparam o desempenho desses jovens com o de estudantes do meio urbano. Contudo, no que diz respeito ao corpo docente, a alta rotatividade cria sérios problemas para a formação em serviço, sejam eles monitores ou professores, fato esse que pode ter implicações no seu desempenho profissional, sobretudo se forem levadas em consideração as especificidades do método da alternância.

\section{A representação social de meio ambiente dos sujeitos da pesquisa}

Mediante o termo indutor "meio ambiente", os sujeitos da pesquisa fizeram 255 evocações utilizando 86 palavras diferentes. Considerando a proximidade semântica entre os vocábulos e as justificativas dadas pelos participantes, as palavras evocadas foram organizadas em 40 categorias distintas, cuja frequência média de evocação - desprezando-se as casas decimais - foi de seis palavras por categoria.

A partir dessa categorização prévia, elegemos para análise as categorias mais salientes, isto é, aquelas que tiveram evocações iguais ou superiores à média. Nessa nova configuração foram identificadas 13 categorias cujas palavras que as compõem foram evocadas 207 vezes, o que corresponde a $81,18 \%$ do total das evocações dos sujeitos da pesquisa. A frequência média de evocação por categoria mais saliente encontrada foi de 15 vocábulos desprezando-se as casas decimais. Por sua vez, a média das ordens médias de evocação encontrada foi de 2,50.

A partir desse conjunto de dados foi possível construir um quadro que permite visualizar melhor os resultados:
Quadro 1 - Distribuição das categorias segundo a frequência média de evocação, a frequência e a ordem média de evocação.

\begin{tabular}{|c|c|c|c|c|c|c|}
\hline fme & categorias & f & $\begin{array}{c}\text { ome } \\
<2,50\end{array}$ & categorias & f & $\begin{array}{c}\text { ome } \\
\geq 2,50\end{array}$ \\
\hline$\geq 15$ & $\begin{array}{l}\text { Água* } \\
\text { Preservação* } \\
\text { Vegetação }\end{array}$ & $\begin{array}{l}30 \\
30 \\
22\end{array}$ & $\begin{array}{l}1,73 \\
1,77 \\
2,32\end{array}$ & $\begin{array}{l}\text { Vida } \\
\text { Degradação }\end{array}$ & $\begin{array}{l}29 \\
15\end{array}$ & $\begin{array}{l}2,72 \\
3,00\end{array}$ \\
\hline$<15$ & $\begin{array}{l}\text { Poluição } \\
\text { Conscientização* } \\
\text { Sustentabilidade* }\end{array}$ & $\begin{array}{l}14 \\
13 \\
11\end{array}$ & $\begin{array}{l}2,43 \\
2,38 \\
1,55\end{array}$ & $\begin{array}{l}\text { Planeta } \\
\text { Ar } \\
\text { Animais } \\
\text { Harmonia } \\
\text { Educação }\end{array}$ & $\begin{array}{c}13 \\
9 \\
9 \\
6 \\
6\end{array}$ & $\begin{array}{l}2,92 \\
2,89 \\
2,78 \\
2,50 \\
3,50 \\
\end{array}$ \\
\hline
\end{tabular}

Fonte: Dados coletados e organizados pelos pesquisadores.

Nota: $\left({ }^{*}\right)$ Elementos mais suscetíveis de pertencer ao núcleo central.

Para a determinação de maior ou menor suscetibilidade de determinada categoria pertencer ao núcleo central da representação, estabeleceu-se que em pelo menos $50 \%$ das vezes os vocábulos evocados que a compõem deveriam ser considerados os mais importantes dentre os quatro citados pelos sujeitos.

Assim, foram identificadas como mais suscetíveis de pertencer ao núcleo central a categoria "água", a qual, além de se destacar por suas 30 evocações, foi considerada como a mais importante em $86,67 \%$ das vezes em que foi lembrada; a categoria "preservação", também com 30 evocações, foi considerada mais importante $80 \%$ das vezes; a categoria "conscientização", com 13 evocações, foi $53,85 \%$ das vezes lembrada como a de maior importância; e a categoria "sustentabilidade", com 11 evocações, teve $72,73 \%$ de importância.

Além disso, as categorias "água", "preservação" e "sustentabilidade" são também as mais prontamente evocadas, isto é, aquelas cujos elementos que as compõem estão dentre os primeiros que vêm à mente dos sujeitos da pesquisa mediante o termo indutor utilizado.

As categorias "água", "preservação", "conscientização" e "sustentabilidade" possivelemente consituem o núcleo central da representação de meio ambiente dos sujeitos, conferindo-lhe determinada significação e organização interna (SÁ, 1996), a qual se demonstrará a seguir. Justifica-se essa afirmação por duas razões principais.

Em primeiro lugar, porque os professores, como todas as demais pessoas, percebem e experienciam um mundo com o qual estão familiarizados (MOSCOVICl, 2003); em outras palavras, as representações desses sujeitos têm a ver com suas experiências cotidianas como docentes em instituições de ensino voltadas para o contexto da agricultura.

Nesse sentido, ainda, nossos resultados se aproximam dos obtidos por Martinho e Talamoni (2007) em seu estudo sobre representações de 
meio ambiente em crianças de uma escola rural e de uma escola urbana. Essas autoras observaram, por exemplo, que as crianças do meio rural mencionavam espécimes da fauna e da flora típicos de seu contexto, com os quais estavam bastante familiarizadas.

Em segundo lugar, porque a pedagogia da alternância enfatiza a necessidade de se promover o desenvolvimento sustentável das propriedades (GIMONET, 2007), o qual, por sua vez, não prescinde da consciência sobre a importância da preservação dos recursos naturais para a agricultura, dentre os quais a água ocupa lugar de destaque.

Especificamente no que diz respeito à categoria "água", formada pelos elementos água, rios, e fontes, o fato de estar dentre as mais salientes, as mais prontamente evocadas e de ser considerada a mais importante, justifica-se em si mesmo. Com efeito, esse recurso natural é tão fundamental para a vida em geral, que a agricultura, cuja atividade consiste em produzir e reproduzir vida, não pode prescindir dele.

Solicitados a justificar suas evocações, bem como a atribuição de importância às palavras escoIhidas relacionadas à água, à preservação, à conscientização e à sustentabilidade, os sujeitos deram respostas tais como:

Docente 4 (CFR Enéas Marques): Porque ainda hoje temos problemas com mata ciliar e poluição das águas por agrotóxicos aplicados indiscriminadamente.

Docente 6 (CFR Marmeleiro): Considerando que devemos com urgência, através de atitudes que contribuem para uma mudança global. Ele (o ambiente) está pedindo socorro... [...] Por perceber a grande necessidade de preservação do meio ambiente, pois necessitamos dele para a nossa sobrevivência. Por isso não podemos nos descuidar do equilíbrio da fauna e da flora.

Outra docente da CFR de Marmeleiro, que mencionou as palavras prevenção, água, lixo e cuidados, nessa ordem, e considerou como mais importantes as palavras prevenção e água, justificou-se como segue:

Docente 2 (CFR Marmeleiro): São as mais importantes, pois, se preservarmos o meio ambiente teremos água em abundância. Para que isso aconteça teremos que ter cuidados especiais e principalmente reciclar o lixo.

Para essa professora, as duas palavras mais importantes, dentre as mencionadas, são prevenção e água, pois, segunda afirma, "[...] dependemos das duas para que tenhamos vida em abundância. Isso só acontecerá se existir preservação".
Esses dados são compatíveis com os achados de Polli e colaboradores (2009). Analisando a representação social de água em educadores, lideranças comunitárias, agricultores, dentre outros grupos residentes em municípios de Santa Catarina, esses autores evidenciaram a necessidade da preservação da água, elemento este fortemente ligado à saúde e à vida para os sujeitos de sua pesquisa.

A centralidade da categoria "preservação" cuja saliência é igual à da categoria "água", a ordem média de evocação é inferior a $2(1,77)$ e a ordem de importância está em $80 \%$ - justifica-se também pela sua pertinência ao contexto da pesquisa. Nas justificativas que vários sujeitos deram para a evocação da categoria, bem como para o grau de importância atribuído à mesma, encontram-se respostas que indicam a necessidade de preservar as matas ciliares, de preservar e proteger fontes e nascentes, de preservar a vida e de não degradar os solos, o ar, os rios e as matas.

Além disso, a ligação dessa categoria com a categoria "água", observada nas ideias de preservação da vida, de proteção de fontes, nascentes e matas ciliares, justifica-se também em relação ao momento atual das Casas Familiares Rurais da região sudoeste do Paraná. De fato, um dos programas governamentais para os agricultores familiares, cujo acesso pelas famílias desses jovens é estimulado pelas CFRs, consiste justamente na política de preservação das nascentes de água, que é apoiada pelo Governo Federal através da Petrobras e da companhia Itaipu Binacional.

Nesse sentido, destaca-se, por exemplo, a menção feita ao programa de proteção de nascentes que está sendo subsidiado pela Petrobras e que é acessado pelas Casas Familiares Rurais da região sudoeste do Paraná. Esse programa visa à manutenção de reserva de água de qualidade para as propriedades familiares, tanto para atendimento das necessidades das famílias e da produção como da sociedade em geral, através da preservação dos mananciais.

A esse respeito, apresentamos a seguir manifestações de dois sujeitos da pesquisa, sendo uma professora da Casa Familiar Rural de São Jorge do Oeste e outra da Casa Familiar Rural de Enéas Marques:

Docente 1 (CFR São Jorge do Oeste): Então, por exemplo, tem um programa de fonte de água, que é através da Petrobras. Nós conseguimos levar a várias famílias, inclusive com a participação dos alunos na proteção de fontes.

Docente 3 (CFR Enéas Marques): Tem o caso do programa que é uma parceria da prefeitura com a Petrobras; que o nosso Presidente da Casa é o responsável do município por essas proteções de 
fontes. Então ele já proferiu palestras, inclusive levou os nossos alunos a assistirem como que faz proteção de fontes e deixou em aberto para os alunos que tivessem necessidade de fazer proteção de fontes, pra ter um privilegio, por ser aluno da casa.

As categorias "conscientização" e "sustentabilidade", por não estarem no quadrante superior esquerdo pelo fato de terem frequência de evocação inferior à média, aparentemente não fazem parte do núcleo central da representação de meio ambiente dos docentes. No entanto, afirmamos a possibilidade de essas categorias pertenceram ao núcleo central por duas razões: em primeiro lugar, pelo fato de as mesmas estarem dentre as mais prontamente evocadas, isto é, abaixo da média das ordens médias de evocação; e, em segundo lugar, por serem consideradas mais importantes em $53,85 \%$ e $72,73 \%$, respectivamente, das vezes em que são evocadas.

A "conscientização" de que falam os docentes liga-se a aspectos como sensibilização, tomada de atitude protagonista em relação à preservação ambiental e exploração consciente dos recursos naturais. A esse respeito, um dado relevante que identificamos consiste no fato de que as justificativas dos sujeitos para a saliência e importância dessa categoria sugerem fortemente a necessidade da sensibilização dos filhos dos agricultores para a preservação da água, recurso vital para a vida em geral e para a agricultura em particular.

Encontramos nesse ponto o que nos parece certa influência das normativas da política nacional de Educação Ambiental, as quais enfatizam que só "quando se inclui também a sensibilidade, a emoção, sentimentos e energias se obtêm mudanças significativas de comportamento" (BRASIL, 1997, p. 183), visando, nesse caso, ao desenvolvimento de valores, conhecimentos e atitudes voltadas à conservação do meio ambiente (BRASIL, 1999). Pode-se notar, também, certa semelhança com a perspectiva conservadora de Educação Ambiental, tal como a conceitua Guimarães (2004). Para esse autor, nessa perspectiva o objetivo da educação enfatiza a mudança no comportamento dos indivíduos em relação às suas práticas no ambiente. Podemos mencionar, ainda, que esses resultados aproximam-se dos obtidos por Abreu, Campos e Aguilar (2008), os quais apontam a preocupação dos professores "em sensibilizar o aluno com relação à preservação do meio ambiente dentro da concepção de que a natureza é um ambiente original e 'puro', no qual os seres humanos estão inseridos" (ABREU; CAMPOS; AGUILAR, 2008, p. 690).

Por sua vez, a categoria "sustentabilidade", formada pelos elementos sustentabilidade e desenvolvimento sustentável, é justificada pelos sujeitos mediante expressões que remetem ao conceito encontrado no "Relatório Brundtland" (SCOTTO, CARVALHO; GUIMARÃES, 2007).

Nas respostas à questão dissertativa sobre desenvolvimento sustentável e nas justificativas para as evocações dadas pelos sujeitos mediante o termo indutor proposto, observa-se certa preocupação com a importância da produção equilibrada para a subsistência da família e satisfação de suas necessidades básicas, levando-se em conta a preservação do meio ambiente para as próximas gerações.

Essa ligação entre sustentabilidade e agricultura prescinde de justificativa. No entanto, vale ressaltar, com dissemos antes, que a pedagogia da alternância enfatiza o desenvolvimento sustentável das propriedades (GIMONET, 2007). Portanto, considerando o contexto da pesquisa, seria estranho se a questão da sustentabilidade não figurasse como central na representação de meio ambiente dos sujeitos. A esse respeito apresentamos a seguir dois fragmentos de respostas de sujeitos para os quais o desenvolvimento sustentável tem a ver com:

Docente 1 (CFR Sulina): preservação da terra, respeitando-se a natureza, visando à subsistência da família e da região, garantindo-se a sobrevivência das próximas gerações.

Docente 5 (CFR Dois Vizinhos): manutenção da prática agrícola necessária para o sustento da família, sem agressão ao meio ambiente, comprometimento com as futuras gerações e com a melhoria na qualidade de vida.

De fato, o desenvolvimento sustentável pressupõe a importância da preservação dos recursos naturais para a agricultura. Por sua vez, a sustentabilidade da agricultura exige a habilidade de manter a produção a despeito dos distúrbios ecológicos (ALTIERI, 1989), bem como a capacidade de encontrar soluções para condicionar a produção à capacidade de suporte dos recursos naturais (ALMEIDA, 1997).

Assim sendo, a se julgar pelos dados obtidos, o núcleo central da representação social de meio ambiente dos docentes das CFRs da região sudoeste do Paraná estabiliza-se em torno da importância atribuída à manutenção de recursos naturais cruciais para a agricultura, sobretudo da água. Tal atitude deve ser estimulada mediante a sensibilização para a preservação ambiental e a exploração sustentável desses recursos.

Em outra situação encontram-se categorias mais ou menos salientes, mais ou menos prontamente evocadas, cuja importância atribuída pelos sujeitos é significativamente inferior às categorias centrais. Nessa situação, que é mais distante do que possivelmente seria o núcleo central da representação de meio ambiente dos sujeitos pesquisados, encontram-se as categorias "vegetação", "poluição", "vida" e "degradação". 
A categoria "vegetação", formada pelos elementos vegetação, árvore, flora, florestas, mata ciliar, mata e planta, é a de maior saliência dentre as categorias periféricas, com 22 evocações. Não obstante, sua importância é considerada em apenas $27,27 \%$ das vezes em que é lembrada. Nas respostas dos sujeitos, essa categoria está frequentemente associada à categoria "degradação" (20 evocações e $20 \%$ de importância), a qual, por sua vez, está ligada ao desmatamento e às queimadas.

Nas justificativas dos sujeitos, observamos que os participantes da pesquisa frequentemente se referem à importância das reservas legais e de atividades como o reflorestamento tanto como uma medida de preservação como de reposição de recursos vegetais degradados. Essa mesma discussão repercutia nos discursos dos estudantes das CFRs na época, cujas famílias estavam preocupadas com a possibilidade de terem de manter como reserva legal $1 / 5$ de suas já pequenas áreas agrícolas. A esse respeito, ressaltamos que na época em que a pesquisa de campo estava sendo realizada, discutia-se muito no sudoeste do Paraná sobre a questão das reservas legais em pequenas propriedades.

A questão mais geral da poluição aparece nas respostas dos sujeitos ligadas aos problemas da poluição do ar e do lixo depositado em locais impróprios ou abandonado, sobretudo nas proximidades de córregos ou fontes. Essa categoria, embora saliente, é pouco importante para os sujeitos $(28,57 \%$ das vezes) e frequentemente não está dentre as mais prontamente evocadas.

Chama a atenção por estar no núcleo periférico da representação social em análise a categoria "vida", formada pelos elementos vida, vida humana, homem e sobrevivência. Sua alta saliência com 29 evocações, bem próxima às das categorias "água" e "preservação", ambas com 30 evocações, contrasta com sua baixa ordem de importância de apenas $44,83 \%$ e com o fato de estar dentre as menos prontamente evocadas.

Dessa forma, à semelhança dos resultados encontrados por Camargo, Luca e Silva (2008), em nossa investigação o elemento humano aparece como periférico na representação social de meio ambiente, na qual são centrais elementos naturais não humanos. Ou seja, o meio ambiente é visto como o lugar dos recursos naturais, os quais precisam ser preservados tendo em vista o atendimento de necessidades futuras; no presente caso, da produção agrícola, ainda que de pequena escala.

Mais distantes ainda do que poderia ser o núcleo central, merecem destaque as categorias "planeta" e "educação". A primeira porque os elementos que a formam - planeta, terra, sol e solo - apesar de serem recursos ou fontes de recursos naturais importantes para a agricultura, são evocados secundariamente e com pouca importância pelos sujeitos. Esse fato contrasta com o que se afirmou acima acerca da importância da preservação da água, que também é um dos mais importantes recursos naturais necessários à criação e manutenção da vida em geral, e da agricultura em particular.

A categoria "educação" está entre as duas de menor saliência, com apenas seis evocações, e é a menos prontamente evocada dentre todas. Não obstante, em $66,67 \%$ das vezes em que a mesma é evocada os sujeitos consideram-na como mais importante em relação às demais.

Além de estar bem distante do que possivelmente seria o núcleo central da representação de meio ambiente, chama a atenção o fato de a categoria "educação" estar associada a elementos tais como Educação Ambiental, orientação e sensibilização, nas respostas dos docentes. Por outro lado, a presença desses elementos poderia justificar a inferência da presença, no corpo docente das CFRs da região sudoeste do Paraná, da perspectiva de Educação Ambiental focada na mudança do comportamento das pessoas e na sua atitude perante os problemas ambientais (GUIMARÃES, 2006; CAMARGO; LUCA; SILVA, 2008), ao invés de uma concepção de Educação Ambiental voltada à transformação de valores, e não apenas de comportamentos.

\section{Considerações Finais}

Os dados discutidos nos sugerem que a representação social de meio ambiente dos docentes das Casas Familiares Rurais da região sudoeste do Paraná, de um lado, ancora-se, objetiva-se e estrutura-se de modo diretamente relacionado com o seu contexto de educadores do campo que vivenciam a realidade de uma modalidade de educação escolar apropriada para filhos de pequenos agricultores; de outro lado, relaciona-se em parte com as mediações propiciadas pela própria condução do trabalho pedagógico pelo método da alternância, o qual coloca o docente frente a frente com a realidade dos educandos. Isto é, os dados que obtivemos nos permitem dizer que a representação social analisada liga-se com características objetivas da situação.

Por outro lado, ainda que os dados nos permitam afirmar que a questão ambiental está presente e contextualizada nas respostas dos sujeitos, isto é, que sua compreensão está conectada com o ambiente da educação do campo, em especial da agricultura familiar, chama a atenção o fato de o elemento humano aparecer de modo apenas periférico na representação social de meio ambiente desses educadores. 
Esse elemento frequentemente aparece associado com vida, vida humana, homem e sobrevivência, e é bem saliente. Não obstante, nunca está dentre os mais prontamente evocados e quando aparece é considerado com menor importância do que elementos mais "naturais", como a água, por exemplo. Por isso, na representação social de meio ambiente dos docentes das CFRs, este é concebido como um lugar de recursos naturais que precisam ser preservados tendo em vista o atendimento de necessidades futuras, em especial da produção agrícola.

E assim, essa concepção de meio ambiente repercute de maneira mais ou menos clara na perspectiva de Educação Ambiental inferida a partir dos dados coletados e analisados. Neste caso, parece tratar-se de uma perspectiva focada na mudança do comportamento das pessoas e na sua atitude perante os problemas ambientais, ao invés de uma concepção voltada à discussão, por exemplo, das razões pelas quais a humanidade vem se deparando com seriíssimos problemas ambientais. No contexto específico, tratar-se-ia de uma educação que, dentre outras temáticas, discutisse que interesses econômicos estão por trás da contaminação dos solos, das águas, dos ares.

Finalmente, tendo em vista que o contexto das CFRs parece exigir dessas instituições que se tornem, também, importantes centros de Educação Ambiental, destacamos a importância de se dirigirem esforços administrativos para aumentar a estabilidade do corpo docente e esforços pedagógicos no sentido de ampliar a concepção de meio ambiente dos professores, particularmente no que diz respeito às relações entre sociedade e natureza.

\section{Referências}

ABREU, D. G.; CAMPOS, M. L. A. M.; AGUILAR, M. B. R. Educação Ambiental nas escolas da região de Ribeirão Preto (SP): concepções orientadoras da prática docente e reflexões sobre a formação inicial de professores de química. Química Nova, São Paulo, v. 31 , n. 3 , p. $688-693,2008$. DOI: 10.1590/S010040422008000300037

ALMEIDA, J. Da ideologia do progresso à idéia de desenvolvimento (rural) sustentável. Porto Alegre: Ed. da Universidade/UFRGS, 1997.

ALMEIDA, L. M. de. Representações sociais e prática pedagógica no processo de construção identitária. In: SANTOS, M. F. S.; ALMEIDA, L. M. (Orgs.). Diálogos com a teoria da representação social. Recife: Editora Universitária da UFPE, 2005. p. 161-200.

ALTIERI, M. A. Agroecologia: as bases científicas da agricultura alternativa. Rio de Janeiro: PTA/FASE, 1989.
BARBIERI, J. C. Desenvolvimento e meio ambiente: as estratégias de mudanças da Agenda 21. Petrópolis: Vozes, 2003.

BARDIN, L. Análise de conteúdo. Lisboa: Edições 70, 2002

BRANDALISE, L. T.; BERTOLINI, G. R. F.; ROJO; C. A.; LEZANA, A. G. R. A percepção e o comportamento ambiental dos universitários em relação ao grau de Educação Ambiental. Gestão \& Produção, São Carlos, v. 16, n. 2, p. 273-285, abr./jun. 2009. DOI: 10.1590/ S0104-530X2009000200010

BRASIL. Ministério da Educação. Parâmetros Curriculares Nacionais: Meio Ambiente e Saúde. Brasília: MEC/SEF, 1997.

. Lei $n^{\circ} 9.795$, de 27 de abril de 1999. (Regulamentada pelo Decreto $n^{\circ} 4.281$, de 25 de junho de 2002). Dispõe sobre a Educação Ambiental, institui a Política Nacional de Educação Ambiental e da outras providências. Diário Oficial da União, Brasília, 28 abr. 1999.

CAMARGO, L. J. de; LUCA, A. Q. de; SILVA, J. P. da. Representações sociais acerca do meio ambiente de moradores do entorno de uma unidade de conservação em Campinas-SP. ENCONTRO NACIONAL DA ANPPAS, 4., Brasília. Anais... Brasília, 2008. p. 1-17.

CARVALHO, I. C. M. Educação Ambiental: a formação do sujeito ecológico. São Paulo: Cortez, 2004.

CASTRO, S. M. V. de. Representação social de ciência de estudantes do Ensino Fundamental da Rede Municipal de Belém - Pará. 2004. 91 f. Dissertação (Mestrado em Educação em Ciências e Matemáticas) - Universidade Federal do Pará, Belém, 2004.

CAVALCANTE, F. G.; MINAYO, M. C. de S. Representações sociais sobre direitos e violência na área da deficiência. Ciência \& Saúde Coletiva, Rio de Janeiro, v. 14, n. 1, p. 57-66, jan./fev. 2009. DOI: 10.1590/S141381232009000100011

CROMACK, L. M. F.; BURSZTYN, I.; TURA, L. F. R. O olhar do adolescente sobre saúde: um estudo de representações sociais. Ciência \& Saúde Coletiva, Rio de Janeiro, v. 14, n. 2, p. 627-634, mar./abr. 2009. DOI: 10.1590/S1413-81232009000200031

DUVEEN, G. O poder das ideias. In: MOSCOVICI, S. Representações sociais: investigações em psicologia social. 4. ed. Petrópolis: Vozes, 2003. p. 7-28.

FRANCO, M. L. B. P. Representações sociais, ideologia e desenvolvimento da consciência. Cadernos de Pesquisa, São Paulo, v. 34, n. 121, p. 169-186, jan./ abr. 2004. DOI: $10.1590 /$ S0100-15742004000100008

FURTADO, C. Os desafios da nova geração. Revista de Economia Política, São Paulo, v. 24, n. 4, p. 483486, out./dez. 2004.

GASTAL, C. L. da C.; GUTFREIND, C. Um estudo comparativo de dois serviços de saúde mental: relações entre participação popular e representações sociais 
relacionadas ao direito à saúde. Cadernos de Saúde Pública, Rio de Janeiro, v. 23, n. 8, p. 1835-1844, ago. 2007. DOI: $10.1590 / S 0102-311 X 2007000800010$

GIMONET, J. C. Praticar e compreender a pedagogia da alternância dos CEFFA's. Petrópolis: Vozes, 2007.

GUIMARÃES, M. Educação Ambiental: no consenso um embate? Campinas: Papirus, 2000.

Armadilha paradigmática na Educação Ambiental. In: LOUREIRO, C. F.; LAYARARGUES, P. P.; CASTRO, R. S. de. (Orgs.). Pensamento complexo, dialética e Educação Ambiental. São Paulo: Cortez, 2006. p. 15-29.

A formação de educadores ambientais. 3 . ed. Campinas: Papirus, 2007.

JACOBI, P. Educação Ambiental, cidadania e sustentabilidade. Cadernos de Pesquisa, São Paulo, n. 118 , p. 189-205, mar. 2003. DOI: 10.1590/S010015742003000100008

LEFF, E. Saber ambiental: sustentabilidade, racionalidade, complexidade, poder. 5. ed. Petrópolis: Vozes, 2001.

LEITE, R. F. B.; VELOSO, T. M. G. Limites e avanços do Programa Saúde da Família de Campina Grande: um estudo a partir de representações sociais. Saúde e Sociedade, São Paulo, v. 18, n. 1, p. 50-62, jan./mar. 2009. DOI: $10.1590 /$ S0104-12902009000100006

LOUREIRO, C. F. Trajetória e fundamentos da Educação Ambiental. São Paulo: Cortez, 2004a.

. Educar, participar e transformar em Educação Ambiental. Revista Brasileira de Educação Ambiental, Brasília, v. 1, p. 13-20, 2004b.

Problematizando conceitos: contribuição à práxis em Educação Ambiental. In: LOUREIRO, C. F.; LAYARARGUES, P. P.; CASTRO, R. S. de. (Orgs.). Pensamento complexo, dialética e Educação Ambiental. São Paulo: Cortez, 2006. p. 104-161.

MARKOVÁ, I. Dialogicidade e representações sociais: as dinâmicas da mente. Petrópolis: Vozes, 2006.

MARTINELLI, G.; CORONA, H. M. P. Considerações sobre gênero na formação de rapazes e moças na casa familiar rural de Sulina - PR. SEMINÁRIO EDUCAÇÃO E DESENVOLVIMENTO, 1., Pato Branco. Anais... Pato Branco: CEPAD/UTFPR, 2007. p. 1-20.

MARTINHO, L. R.; TALAMONI, J. L. B. Representações sobre meio ambiente de alunos da quarta série do Ensino Fundamental. Ciência \& Educação, Bauru, v. 13 , n. 1, p. 1-13, jan./abr. 2007. DOI: 10.1590/S151673132007000100001

MINAYO, M. C. de S. Pesquisa social: teoria, método e criatividade. 22. ed. Rio de Janeiro: Vozes, 2003.

O conceito de representações sociais $\overline{\text { dentro }}$ da sociologia clássica. In: GUARESCHI, P.; JOVCHELOVITCH, S. (Orgs.). Textos em representações sociais. 10. ed. Petrópolis: Vozes,
2008. p. 89-111.

MOSCOVICI, S. Representações sociais: investigações em psicologia social. 4. ed. Petrópolis: Vozes, 2003.

POLLI, G. M. et. al. Representações sociais da água em Santa Catarina. Psicologia em Estudo, Maringá, v. 14 , n. 3 , p. 529-536, jul./set. 2009. DOI: 10.1590/ S1413-73722009000300014

REIGOTA, M. Meio ambiente e representação social. 7. ed. São Paulo: Cortez, 2007.

SÁ, C. P. Núcleo central das representações sociais. Petrópolis: Vozes, 1996.

SCHWARZ, M. L.; SEVEGNANI, L.; ANDRÉ, P. Representações da mata atlântica e de sua biodiversidade por meio dos desenhos infantis. Ciência \& Educação, Bauru, v. 13, n. 3, p. 369-388, set./dez. 2007. DOI: $10.1590 /$ S1516-73132007000300007

SCOTTO, G.; CARVALHO, I. C. de M.; GUIMARÃES, L. B. Desenvolvimento Sustentável. Petrópolis: Vozes, 2007.

Nota: os autores agradecem ao Conselho Nacional de Desenvolvimento Científico e Tecnológico - CNPq pelo apoio financeiro concedido à da pesquisa e à Fundação Araucária de Apoio ao Desenvolvimento Científico e Tecnológico do Paraná pela concessão de uma bolsa de Iniciação Científica.

Recebido em 15/04/2011

Versão final recebida em 29/08/2011

Aceito em 05/09/2011 